\title{
МОРФОЛОГИЯ И СВОЙСТВА ПЛЕНОК ZnO, ПОЛУЧЕННЫХ МЕТОДОМ МНОГОКРАТНОГО ЦЕНТРИФУГИРОВАНИЯ НА ПОДЛОЖКАХ ПОРИСТОГО КРЕМНИЯ
}

\author{
(C) 2016 г. В. С. Захвалинский ${ }^{1,}$ *, И. М. Голев², Л. В. Борисенко ${ }^{1}$, \\ Т. В. Прокопова ${ }^{2}$, А. Н. Хмара ${ }^{1}$, Е. А. Пилюк ${ }^{1}$, Д. А. Колесников ${ }^{1}$ \\ ${ }^{1}$ Белгородский государственный национальный исследовательский университет, Белгород \\ ${ }^{2}$ Военный учебно-научный иентр военно-воздушных сил “Военно-воздушная академия”, \\ имени профессора Н.Е. Жуковского и Ю. А. Гагарина, Воронеж \\ *E-mail: zakhvalinskii@bsu.edu.ru
}

\begin{abstract}
Были получены слои пористого кремния (PS), многослойные пленки ZnO и гетероструктуры на их основе. Методами рентгеноспектрального энергодисперсионного анализа (EDX), рентгенофазового анализа (РФА) и растровой электронной микроскопии (РЭМ) была исследована морфология поверхности, химический и фазовый состав слоя PS и пленок ZnO, поперечный скол нанокомпозита (ZnO-PS). Проведены исследования вольт-амперных характеристик гетероструктур $\mathrm{Al} / \mathrm{Ag} / p-\mathrm{Si}(100) / \mathrm{PS} / \mathrm{ZnO} / \mathrm{Ag} / \mathrm{Al}$ и $\mathrm{Al} / \mathrm{Ag} / p-\mathrm{Si}(100) / \mathrm{PS} / \mathrm{ZnO} / \mathrm{SiC} / \mathrm{Ag} / \mathrm{Al}$.
\end{abstract}

DOI: $10.7868 / \mathrm{S} 0367676516090556$

\section{ВВЕДЕНИЕ}

Оксид цинка ( $\mathrm{ZnO})$ - это широкозонный полупроводник с широким практическим применением, включающим катализаторы, датчики газов, химические сенсоры, приборы на акустических поверхностных волнах, солнечные элементы [1-3] и оптоэлектронные приборы [4]. Одно из направлений повышения эффективности источников белого света на основе $\mathrm{ZnO}$ - применение нанокомпозитов. Развитые поверхности слоев пористого кремния (PS) являются хорошими подложками для нанокомпозитных источников белого света на основе ZnO. Установлено, что композиты оксид цинка-пористый кремний (ZnO-PS) демонстрируют возрастание эмиссии белого света в диапазоне электромагнитного спектра от 1.4 до 3.3 эВ [5]. Распространенным решением при создании интенсивного источника белого света является смешение излучений красного, зеленого и голубого светодиодов [6]. Эффективность такого источника белого света подтверждается результатами исследования фотолюминесценции ( $\mathrm{ZnO}-\mathrm{PS}$ ) нанокомпозита при возбуждении (3.81) эВ НеСd-лазером. В интенсивном спектре интервала от 1.4 до 3.3 эВ наблюдается наличие трех пиков красного (1.69 эВ), зеленого (2.34 эВ) и голубого (2.88 эВ) [5]. Гетероструктуры на основе (ZnO-PS) нанокомпозита получают влажным золь-гельным методом с использованием центрифугирования [7] и высоко частотным напылением ZnO на подложку PS [8]. Применяются раз- личные методы получения наноразмерных образцов $\mathrm{ZnO}$, которые направлены на использование электронных, оптических и пьезоэлектрических свойств оксида цинка [9]. Например, при разработке низкопороговых ультрафиолетовых лазеров, работающих при комнатной температуре [10, 11].

Следовательно, получение диодных структур на основе пористого кремния и оксида цинка является актуальной задачей. Настоящая статья посвящена получению пористого кремния, нанесению слоев $\mathrm{ZnO}$ методом многократного центрифугирования (sol-gel spin coating method), исследованию композита (ZnO-PS) и диодных гетероструктур на его основе.

\section{ЭКСПЕРИМЕНТ}

Слой PS был получен электрохимическим травлением пластин монокристаллического кремния $p$-типа проводимости марки КДБ-2 с кристаллографической ориентацией (100). Перед травлением на неполированную сторону кремния, предварительно очищенную от слоя $\mathrm{SiO}_{2}$, последовательно наносили методом термического вакуумного напыления: пленка алюминия и, поверх нее, пленка серебра. Нанесение обратного металлического электрода - это часть процесса получения пористого кремния методом анодирования в растворе. Для создания надежного омического контакта пленки отжигались в вакуумной печи при температуре $450^{\circ} \mathrm{C}$ в течение 30 минут. 
Торцы образцов защищались от подтравливания слоем парафина. Травление было проведено в электролите состава: $\mathrm{HF}(48 \%): \mathrm{C}_{2} \mathrm{H}_{5} \mathrm{OH}=1: 1$, в режиме постоянного тока при перемешивании электролита. Падение напряжения на электрохимической ячейке составляло порядка 1.2-1.8 В. Промывка образцов осуществлялась изопропиловым спиртом, ацетоном и петролейным эфиром.

Далее образцы покрывались оксидом цинка методом центрифугирования по следующей технологии. К 0.3 моль $\cdot \pi^{-1}$ раствору ацетата цинка $\mathrm{Zn}(\mathrm{CH} 3 \mathrm{COO}) 2 \cdot 12 \mathrm{H}_{2} \mathrm{O}$ в этиловом спирте, был добавлен 0.3 моль $\cdot \pi^{-1}$ раствор моноэтаноламина (МЭА) в соотношении $1: 1$. Полученный раствор наносился $N=7$ раз на поверхность PS, после каждого нанесения образец подвергался центрифугированию, затем предварительному отжигу в течение 10 минут при $T=275^{\circ} \mathrm{C}$. Процесс получения многослойной пленки $\mathrm{ZnO}$ завершался отжигом многослойных образцов в течение 10 минут при $T=650^{\circ} \mathrm{C}$.

Фазовой состав и кристаллическую структуру полученных пленок $\mathrm{ZnO}$ исследовали методом рентгенофазового анализа на дифрактометре Rigaku IV, съемка $\theta-2 \theta$, в диапазоне углов $10-$ 100 град, фильтр Ni $K_{\beta}, \mathrm{Cu} K_{\alpha} \lambda=1.54056 \AA$, без монохроматора, в геометрии Брен-Брентано. Было установлено, что полученные пленки состояли из гексагонального оксида цинка пространственная группа $\mathrm{P}_{3} \mathrm{mc}(a=3.2533 \AA, c=5.2073 \AA)$. Химический состав полученных пленок контролировался методом энергодисперсионной рентгеновской спектроскопии (EDX). Было установлено, что состав пленок соответствовал ZnO. Спектры EDX, поперечное сечение нанокомпозита (ZnO-PS) и морфология поверхности пленки $\mathrm{ZnO}$ исследованы на сканирующем электронном микроскопе Quanta 600 3D и Nova Nano 450.

После нанесения методом термического напыления омических контактов $\mathrm{Al} / \mathrm{Ag}$ была получена гетероструктура $\mathrm{Al} / \mathrm{Ag} / p-\mathrm{Si}(100) / \mathrm{PS} / \mathrm{ZnO} / \mathrm{Ag} / \mathrm{Al}$.

Методом ВЧ-магнетронного нереактивного напыления был нанесен дополнительный пассивирующий слой $\mathrm{SiC}$ и получена гетероструктура $\mathrm{Al} / \mathrm{Ag} / p-\mathrm{Si}(100) / \mathrm{PS} / \mathrm{ZnO} / \mathrm{SiC} / \mathrm{Ag} / \mathrm{Al}$.

Были проведены исследования вольт-амперных характеристик обеих гетероструктур.

\section{РЕЗУЛЬТАТЫ И ОБСУЖДЕНИЕ}

Нами был исследован процесс образования пор в $p$ - $\mathrm{Si}(100)$ при анодировании в электролите на основе этилового спирта. Образцы оказались покрыты углублениями со сферической поверхностью - островками травления, начальной фазы образования

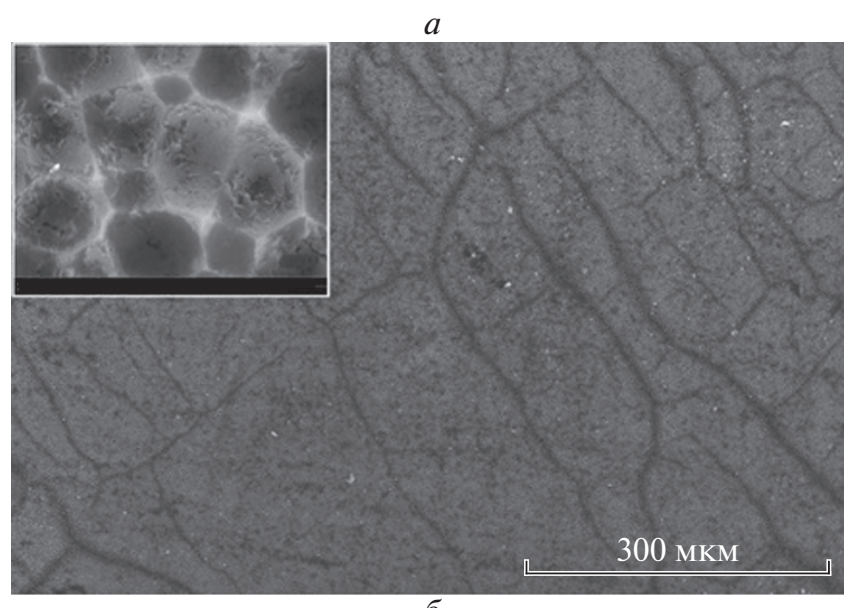

$\sigma$

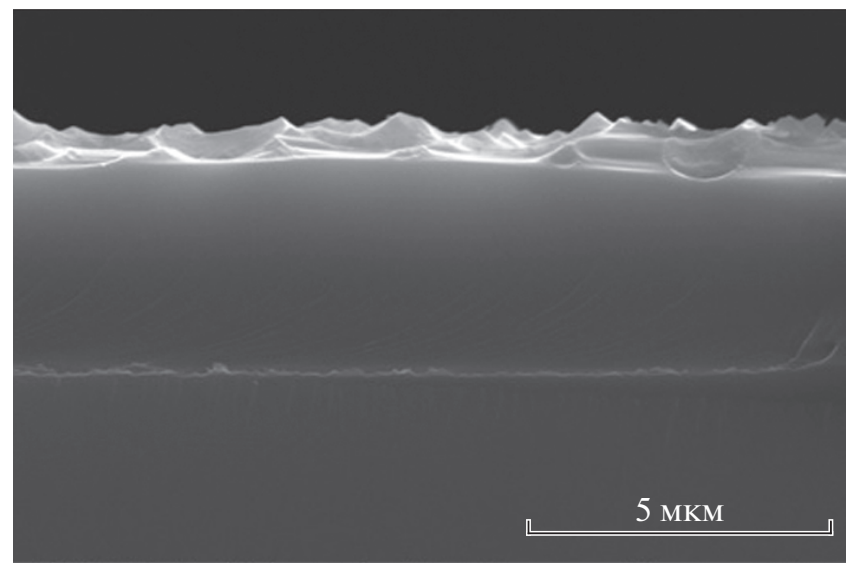

Рис. 1. Морфология поверхности $p-\mathrm{Si}(100)$ в начале образования PS $(a)$, на вставке с увеличением в 50000 раз и изображение скола образца $p$-Si (100) на начальном этапе анодирования (б).

пор, плотность тока составляла $j=25 \mathrm{MA} \cdot \mathrm{cm}^{-2}$, а время травления $t=15$ мин. Результаты исследования морфологии поверхности и скола образца в электронном сканирующем микроскопе приведены на рис. 1. При дальнейшем травлении на поверхности образца, начинают проступать более светлые квадратные контуры - субячейки. Субячейки образованы кристаллическими плоскостями (001), перпендикулярными поверхности. На рис. $2 a$ видны субячейки слоя макропористого кремния, а на рис. 26 показано изображение скола образца $\mathrm{PS} / p-\mathrm{Si}(100)$, полученного при плотности тока $j=15 \mathrm{MA} / \mathrm{cm}^{2}$ и времени травления $t=50$ минут. Данные условия анодирования обеспечили образование на поверхности образца слоя макропористого кремния толщиной 9.7 мкм и средним диаметром пор 1.92 мкм.

После получения слоев пористого кремния на образцы наносился слой раствора ацетата цинка 


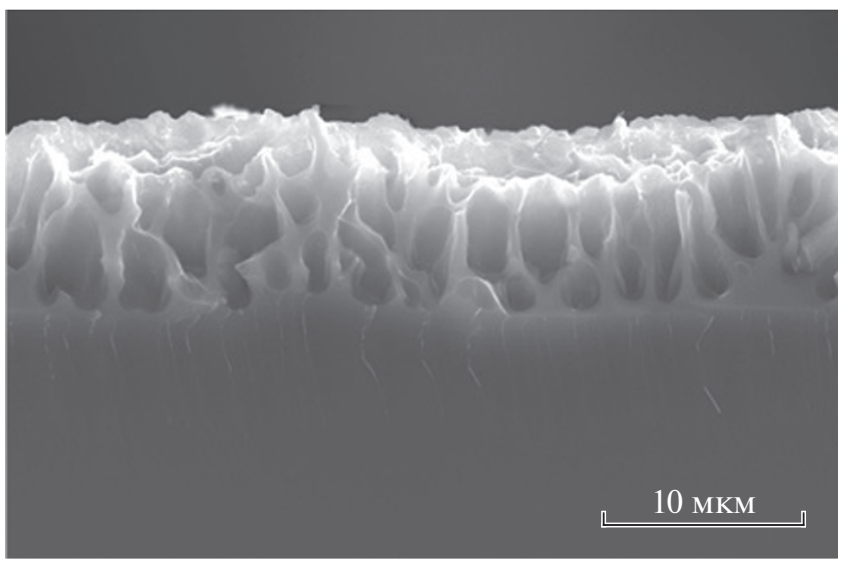

$\sigma$

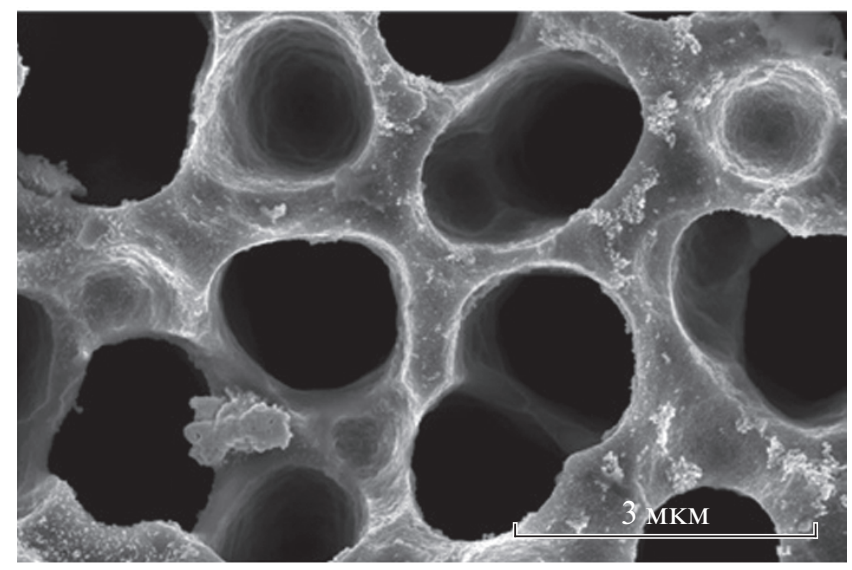

Рис. 2. Изображение поверхности PS $(a)$ и скола образца $\mathrm{PS} / p$-Si (100) (б), полученного при плотности тока $j=15 \mathrm{MA} \cdot \mathrm{cm}^{-2}$ и времени травления $t=50 \mathrm{мин.}$

и моноэтаноламина в этиловом спирте, предварительно выдержанного до образования золь-геля. Методом центрифугирования в сочетании с сушкой и отжигом была получена пленка ZnO.

Морфология поверхности пленки $\mathrm{ZnO}$, нанесенной на слой пористого кремния, была исследована на сканирующих электронных микроскопах Quanta 600 3D и Nova Nano 450. На рис. $3 a$ представлено поперечное сечение гетероструктуры ZnO/PS, полученное на сканирующем электронном микроскопе Quanta 600 3D. На сколе хорошо видна ячеистая структура пористого кремния. На рис. $3 б$ приведен результат исследования морфологии поверхности многослойного покрытия ZnO. Как видно из рис. 3б, пленки ZnO обладают развитой поверхностью и покрыты трещинами. Использованная технология нанесения зольгеля методом центрифугирования с последующи-

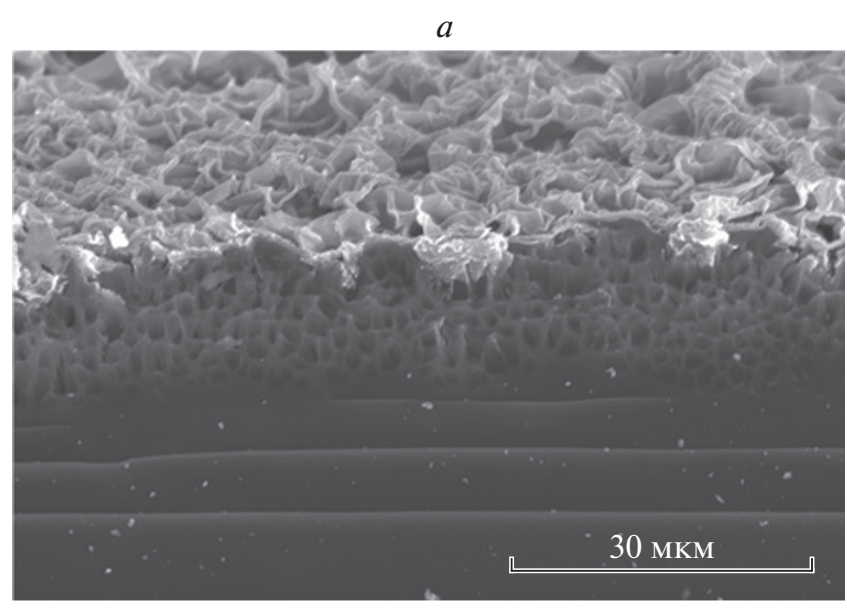

$\sigma$

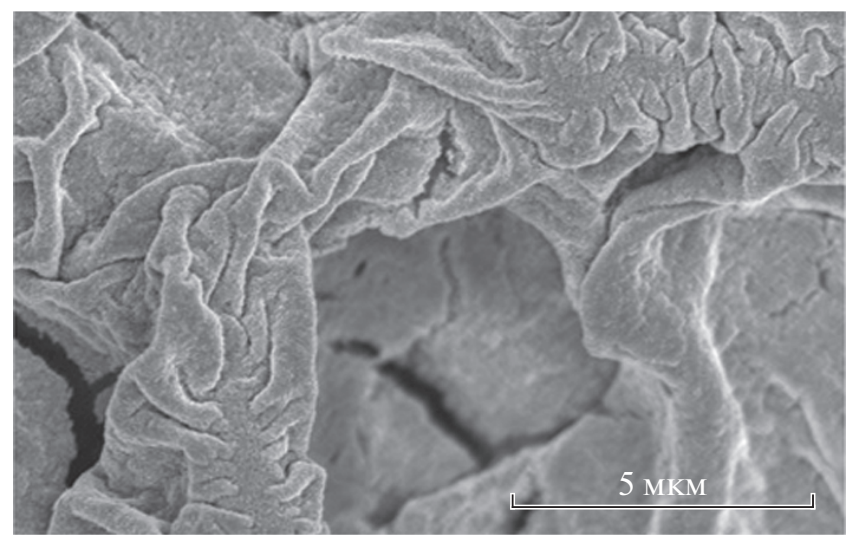

Рис. 3. Поверхность пленки ZnO: $a$ - поперечное сечение гетероструктуры ZnO/PS, полученное на сканирующем электронном микроскопе Quanta 600 3D; $\sigma$ - поверхность внешнего слоя пленки $\mathrm{ZnO}$.

ми отжигами обеспечивает сплошное покрытие только в случае многослойной пленки $\mathrm{ZnO}$.

Было проведено исследование вольт-амперных характеристик гетероструктур $\mathrm{Al} / \mathrm{Ag} / p-\mathrm{Si}(100) /$ $\mathrm{PS} / \mathrm{ZnO} / \mathrm{Ag} / \mathrm{Al}$ и $\mathrm{Al} / \mathrm{Ag} / p-\mathrm{Si}(100) / \mathrm{PS} / \mathrm{ZnO} / \mathrm{SiC} /$ $\mathrm{Ag} / \mathrm{Al}$ при комнатной температуре. Как видно из рис. $4 a$ использованная технология центрифугирования с последующими отжигами позволила создать диодную гетероструктуру на основе пористого кремния и $\mathrm{ZnO}$.

Характеристики диодной структуры были существенно улучшены после нанесения пассивирующего слоя $\mathrm{SiC}$. Как видно из рис. $4 б$ прямой максимальный ток в гетероструктуре $\mathrm{Al} / \mathrm{Ag} / p-\mathrm{Si}(100) /$ $\mathrm{PS} / \mathrm{ZnO} / \mathrm{SiC} / \mathrm{Ag} / \mathrm{Al}$ увеличился почти на два порядка и обратное максимальное напряжение более чем в 4 раза по сравнению с гетероструктурой $\mathrm{Al} / \mathrm{Ag} / p-\mathrm{Si}(100) / \mathrm{PS} / \mathrm{ZnO} / \mathrm{Ag} / \mathrm{Al}$. 
$a$
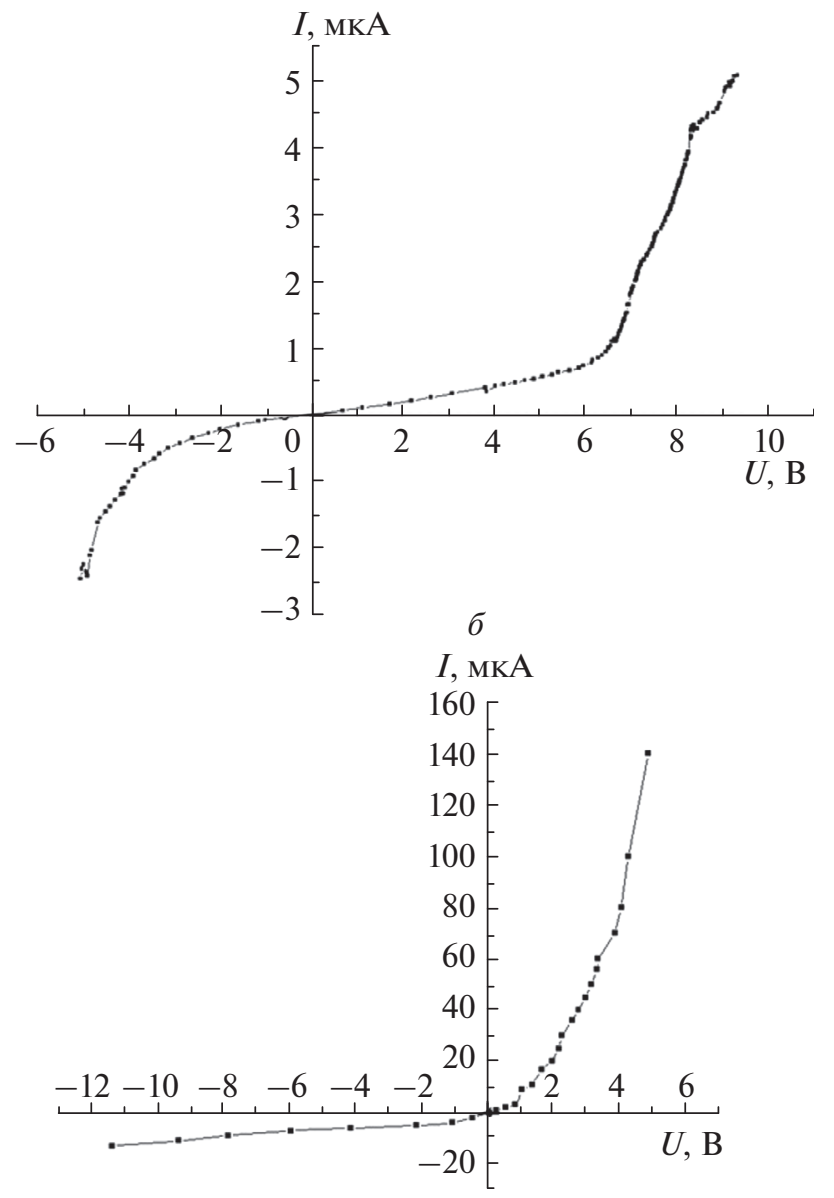

Рис. 4. Вольт-амперные характеристики гетероструктур: $a-\mathrm{Al} / \mathrm{Ag} / p-\mathrm{Si}(100) / \mathrm{PS} / \mathrm{ZnO} / \mathrm{Ag} / \mathrm{Al} ; \sigma-\mathrm{Al} / \mathrm{Ag} /$ $p$-Si(100)/PS/ZnO/SiC/Ag/Al.

\section{ВЫВОДЫ}

На подложках монокристаллического $p-\operatorname{Si}(100)$ были получены слои пористого кремния методом анодирования в растворе. Методом многократного центрифугирования, разложения, сушки и отжига золь-гельных слоев (sol-gel spin coating method) были получены многослойные пленки ZnO. Texнология получения пленок основана на многократном нанесении слоев растворов ацетата цинка $\mathrm{Zn}\left(\mathrm{CH}_{3} \mathrm{COO}\right)_{2} \cdot 12 \mathrm{H}_{2} \mathrm{O}$ в изопропиловом спирте и моноэтаноламине и на их термическом разложении. Методами рентгеноспектрального энергодисперсионного анализа (EDX), рентгенофазового анализа (РФА) и растровой электронной микроскопии (РЭМ) были исследованы морфология поверхности, химический и фазовый состав пленок ZnO. Методом ВЧ-магнетронного напыления на поверхность ZnO был нанесен пассивирующий слой $\mathrm{SiC}$. Было проведено исследование вольт-амперной характеристики полученной гетероструктуры $\mathrm{Al} / \mathrm{Ag} / p-\mathrm{Si}(100) / \mathrm{PS} / \mathrm{ZnO} /$ $\mathrm{Ag} / \mathrm{Al}$. Показано, что нанесение пассивирующего слоя $\mathrm{SiC}$ на многослойную пленку $\mathrm{ZnO}$ улучшает свойства диодной гетероструктуры. Полученная в результате гетероструктура $\mathrm{Al} / \mathrm{Ag} / p-\mathrm{Si}(100) / \mathrm{PS} /$ $\mathrm{ZnO} / \mathrm{SiC} / \mathrm{Ag} / \mathrm{Al}$ обладала большим прямым максимальным током и максимальным обратным напряжением.

Работа была поддержана Российским фондом фундаментальных исследований, проект № 15-42-03192. Исследования были проведены на научном оборудовании Центра коллективного пользования “Диагностика структуры и свойств наноматериалов” Белгородского государственного национального исследовательского университета, при финансовой поддержке Министерства образования и науки РФ в рамках проекта № 14.594.21.0010, уникальный код RFMEFI59414X0010.

\section{СПИСОК ЛИТЕРАТУРЫ}

1. Nomura K., Ohta H., Ueda K. et al. // Science. 2003. V. 300. P. 1269.

2. Huang M.H., Mao S., Feick H. et al. // Science. 2001. V. 292. P. 1897.

3. Lee C.T., Su Y.K., Wang H.M. // Thin Solid Films. 1987. V. 150. P. 283.

4. Yamamoto T., Katayama-Yoshida H. // Jap. J. Appl. Phys. 1999. V. 38. P. L166.

5. Singh R.G., Singh F., Kanjilal D. et al. // J. Phys. D: Appl. Phys. 2009. V. 42. P. 062002.

6. Schubert E.F. // Light Emitting Diodes. Cambridge: Cambridge Univ. Press, 2nd. 2006. P. 431.

7. Kim Y.-S., Taib W.-P., Shu S.-J. // Thin Solid Films. 2005. V. 491. P. 153.

8. Kayahan E. // J. Lumin. 2010. V. 130. P. 1295.

9. Nikoobakht B. // Chem. Mater. 2007. V. 19. № 22. P. 5279.

10. Ли Л.Е., Демьянец Л.Н., Никитин С.И., Лавриков А.С. // Квантовая электрон. 2006. Т. 36. С. 233.

11. Демьянец Л.Н., Ли Л.Е., Уварова Т.Г., Мининзон Ю.М. // Неорган. матер. 2008. Т. 44. С. 45. 